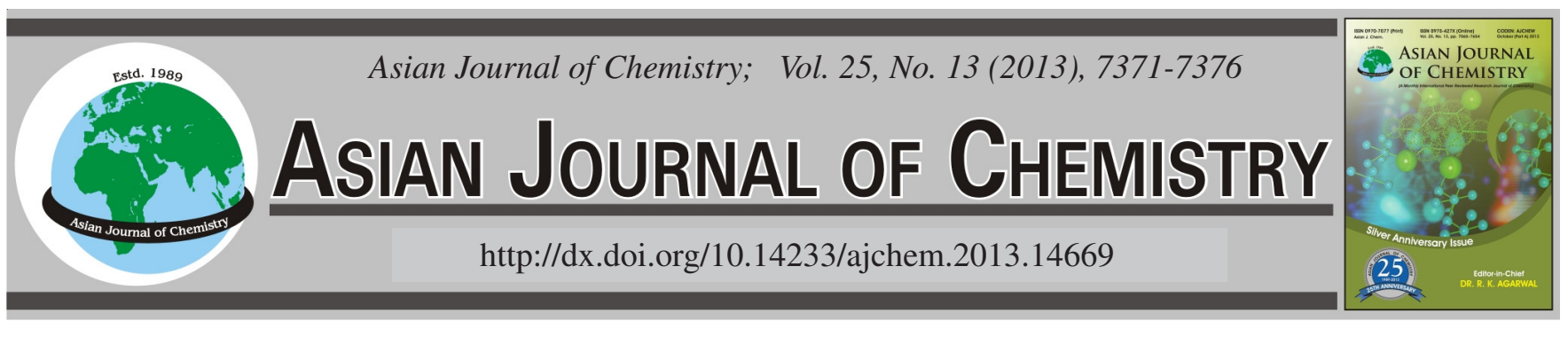

\title{
Synthesis, Characterization and Quantum Chemical Studies of Some Co(II) and Cu(II) Complexes of Acetoacetic Acid Hydrazide
}

\author{
F.A.O. AdeKunle* ${ }^{*}$ B. Semire and O.A. Odunola
}

Department of Pure and Applied Chemistry, Ladoke Akintola University of Technology, Ogbomoso, Nigeria

*Corresponding author: Tel: +234 8035821847; E-mail: fnnmy2001@yahoo.com

\begin{abstract}
New complexes of cobalt(II) and copper(II) acetoacetic acid hydrazides have been synthesized and characterized by elemental analysis, infrared and electronic reflectance spectra and room temperature magnetic susceptibility measurements. The infrared spectra of the complexes revealed the coordination to the metal ion occurs at the carbonyl oxygen and the amino nitrogen of the hydrazide moiety. This was supported by theoretical calculations. The conjoint of the electronic spectra and magnetic susceptibility measurements suggests plausible octahedral geometry for the cobalt(II) complexes while the copper(II) complexes adopt a square planar geometry. The stereochemistry of the modeled structures calculated by semi-empirical (PM3) and density functional theory (DFT) methods are also consistent with those experimentally deduced.
\end{abstract}

Key Words: Synthesis, Infrared, Hydrazides, DFT, Electronic spectra.

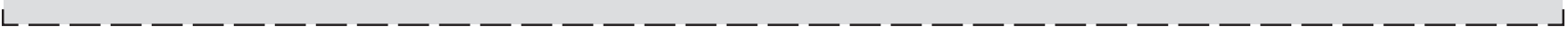

\section{INTRODUCTION}

Transition metal complexes of hydrazides have been intensely investigated by coordination chemists because of their interesting structural properties and their wide ranging applications ${ }^{1-5}$. Aliphatic carboxylic acid hydrazides among many other uses are employed as metal ion removal from waste waters ${ }^{6}$, aromatic hydrazides are used as stabilizers for rigid PVC against therm-oxidative degradation ${ }^{7}$. Hydrazides are also used for the extraction of non-ferrous metals and rare earth from aqueous solutions $\mathrm{s}^{8-10,11}$. The coordinating ability of hydrazides to a variety of elements particularly transition metals afford the study of the metals in such systems.

In continuation of our studies on alkyl acetoacetate hydrazides ${ }^{12,13}$ we present the results of our investigations on the synthesis, spectral and the theoretical studies of $\mathrm{Co}$ (II) and $\mathrm{Cu}$ (II) complexes of acetoacetic acid hydrazide. The complexes are new and represent the first systematic study of acetoacetic acid hydrazide series.

\section{EXPERIMENTAL}

Reagents grade cobalt(II) acetate tetrahydrate, cobalt(II) chloride hexahydrate, cobalt(II) sulphate heptahydrate, copper(II) acetate monohydrate, copper(II) chloride dihydrate, copper(II) sulphate pentahydrate, copper(II) nitrate pentahydrate, ethylacetoacetate, hydrazine hydrate, methanol were available from $\mathrm{BDH}$.
Preparation of acetoacetic acid hydrazide: Ethylaceto acetate $(51 \mathrm{~mL}, 0.04 \mathrm{~mol})$ was added dropwisely to hydrazine hydrate $(19.4 \mathrm{~mL} 0.04 \mathrm{~mol})$ in quick fit conical flask fitted with a reflux condenser. The orange coloured suspension obtained was refluxed for $15 \mathrm{~min}$ and on addition of $170 \mathrm{~mL}$ of ethanol a clear yellow solution was obtained. The resultant solution was refluxed for an additional $4 \mathrm{~h}$ after which the ethanol was distilled off. The remaining solution was transferred to a $250 \mathrm{~mL}$ beaker and left overnight at room temperature. The precipitate was filtered by suction, washed with deionized water and dried in a desiccator over calcium chloride (yield $17.2 \mathrm{~g} ; 63 \%$ ).

Synthesis of $\left[\mathrm{Cu}(\mathrm{AAAH})_{2}\right](\mathrm{OAc})_{2}$ : Acetoacetic acid hydrazide $(3.48 \mathrm{~g}, 0.003 \mathrm{~mol})$ dissolved in $10 \mathrm{~mL}$ methanol was added dropwisely to $\mathrm{Cu}(\mathrm{OAc})_{2} \cdot 4 \mathrm{H}_{2} \mathrm{O}(2.99 \mathrm{~g}, 0.0015 \mathrm{~mol})$ dissolved in methanol $(30 \mathrm{~mL}, 40 \%)$ with stirring on a magnetic stirrer. Ammonia was added to raise the $\mathrm{pH}$ to 9 to aid precipitation. The resulting mixture was left to stir for $1 \mathrm{~h}$ after which it was filtered by suction, washed with $40 \%$ methanol and deionized water and dried over calcium chloride (yield $3.4 \mathrm{~g}$ $55 \%$ ). The other complexes of $\mathrm{Co}$ (II) and $\mathrm{Cu}$ (II) were similarly prepared.

Physical measurements: Microanalysis for carbon, hydrogen and nitrogen for the ligand and complexes were determined using a Perkin-Elmer 240C elemental analyzer. The percentage metal was determined using complexometric method ${ }^{14}$. Infrared spectra were recorded on a Nicolet Avatar 
330 FT-IR spectrophotometer in nujol. Electronic reflectance spectra of the ligand and complexes in nujol were recorded using Genesys 10 scanning spectrophotometer (Thermo Electron Corporation).

Computational details: $\mathrm{The} \mathrm{Co}(\mathrm{II})$ and $\mathrm{Cu}$ (II) complexes were modeled based on the spectroscopic interpretations which involved the $\mathrm{O} 2$ and N2 atoms (Fig. 1) forming coordinate bonds with metal ions using Spartan program (Spartan 06) implemented on an Intel Pentium M $2.0 \mathrm{GHz}$ computer. Other possibilities involving $\mathrm{O} 1$ and N2 in ligand-metal bonds were considered. Three copper(II) complex ions and two cobalt(II) complex ions were modeled to determine their thermodynamic stability as shown in Fig. 1. The optimization and frequency calculation of both the $\mathrm{Cu}$ (II) complexes and $\mathrm{Co}$ (II) complexes were performed using both semi-empirical method (PM3) and DFT (B3LYP/6-31G*) DFT levels of calculations based on the preliminary stability study. Semi-emperical method (PM3) was considered along with DFT since PM3 have been successfully used either alone or with other theoretical methods for structural analysis of $\mathrm{Cu}$ (II) complexes ${ }^{15-20}$. Density functional theory (DFT) calculations were performed with the hybrid B3LYP exchange and correlation functional ${ }^{21,22}$ and 6-31G(d) basis set. All calculations carried out both at PM3 and DFT levels are without symmetry restriction.

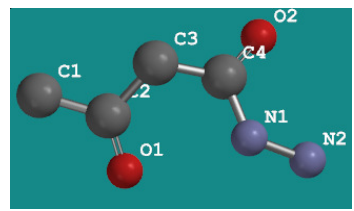

Ligand

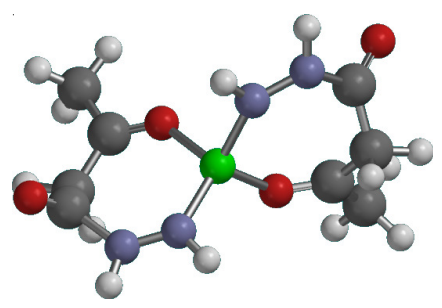

B

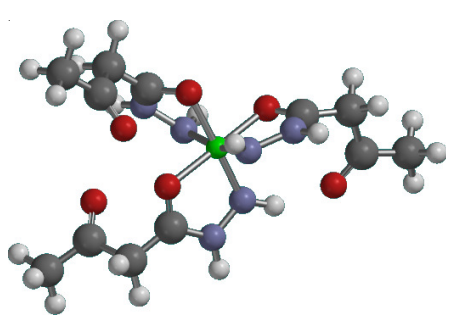

D

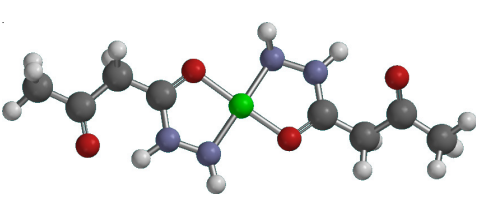

A

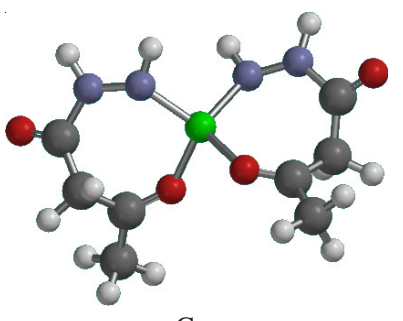

C

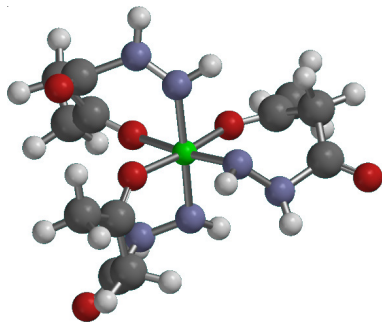

E
Fig. 1. Optimized structures of the ligand and complex ions: $(\mathrm{A})=\mathrm{Cu}(\mathrm{II})$ complex ion (square planar), (B) = Cu(II) complex ion (trans-), (C) $=\mathrm{Cu}(\mathrm{II})$ complex ion $($ cis- $),(\mathrm{D})=\mathrm{Co}(\mathrm{II})$ complex ion (octahedral) and $(\mathrm{E})=\mathrm{Co}(\mathrm{II})$ complex ion (bend octahedral)

\section{RESULTS AND DISCUSSION}

The formation of acetoacetic acid hydrazide proceeded generally in appreciable yields as shown in the following equations: $\mathrm{CH}_{3} \mathrm{COCH}_{2} \mathrm{COOR}^{\prime}+\mathrm{H}_{2} \mathrm{NNH}_{2} \rightarrow \mathrm{CH}_{3} \mathrm{COCH}_{2} \mathrm{CONHNH}_{2}$ $+\mathrm{R}^{\prime} \mathrm{OH}$
The reaction of the metal salts and the ligand to form complexes can be represented as:

$$
\begin{aligned}
& \mathrm{MX}_{2} \cdot \mathrm{xH}_{2} \mathrm{O}+2 \mathrm{CH}_{3} \mathrm{COCH}_{2} \mathrm{CONHNH}_{2} \rightarrow \mathrm{M}\left[\mathrm{CH}_{3} \mathrm{COCH}_{2}-\right. \\
& \mathrm{M}=\mathrm{Co} \\
& \left.\mathrm{CONHNH}_{2}\right]_{2}+\mathrm{xH}_{2} \mathrm{O} \\
& \mathrm{MX}_{2} \cdot \mathrm{xH}_{2} \mathrm{O}+2 \mathrm{CH}_{3} \mathrm{COCH}_{2} \mathrm{CONHNH}_{2} \rightarrow \mathrm{M}\left[\mathrm{CH}_{3} \mathrm{COCH}_{2}-\right. \\
& \left.\mathrm{CONHNH}_{2}\right]_{2}+\mathrm{xH}_{2} \mathrm{O} \\
& \mathrm{M}=\mathrm{Cu}
\end{aligned}
$$

The analytical data for the ligand and complexes are presented in Table-1. The complexes were obtained in different shades of colours ranging from purple to green. The complexes obtained as solids display very poor solubility in protic and non-coordinating solvents; hence the single crystals X-ray diffraction studies of any of the compounds could not be studied.

Infrared spectra of ligand and complexes: The infrared spectra bands (Table-2) were assigned by critically comparing the spectra of the free ligand with those of the complexes. There are three major vibrations that have been used successfully to infer coordination of ligands to the metal in the spectra of complexes of hydrazides. These are the carbonyl stretching frequency $\left[v_{\mathrm{s}}(\mathrm{C}=\mathrm{O})\right]$ or the 'amide 1 ', the in-plane bending deformation and stretching frequency for cyanate $[\delta(\mathrm{N}-\mathrm{H})+$ $\mathrm{V}_{\mathrm{s}}(\mathrm{C}-\mathrm{N})$ ] or the 'amide II' and the amino stretching vibrations $\mathrm{V}_{\mathrm{s}}\left(\mathrm{NH}_{2}\right)$. In the spectra of the acetoacetic acid hydrazide the absorption band observed at $1612 \mathrm{~cm}^{-1}$ is assigned to the $\mathrm{v}(\mathrm{C}=\mathrm{O})$, the carbonyl stretching mode called "amide $1 "$. The band was also observed at 1614 and $1704 \mathrm{~cm}^{-1}$ from DFT and PM3 quantum mechanical calculations. These vibrations experienced a bathochromic shift on coordination to the $\mathrm{Co}$ (II) metal to $1570-1566 \mathrm{~cm}^{-1}$. In the modeled Cobalt(II) complex ion the 'amide 1' band was observed between 1672-1600 and $1598-1552 \mathrm{~cm}^{-1}$ for PM3 and DFT calculations, respectively. The similar band for the $\mathrm{Cu}$ (II) complexes were experimentally observed between $1566-1563 \mathrm{~cm}^{-1} ; 1645-1642 \mathrm{~cm}^{-1}$ for PM3 and $1584-1545 \mathrm{~cm}^{-1}$ for DFT calculations.

The "amide II" band was observed at $1544 \mathrm{~cm}^{-1}$ in the acetoacetic hydrazide ligand. This band was found at 1620 $\mathrm{cm}^{-1}$ for PM3 and $1540 \mathrm{~cm}^{-1}$ for DFT calculations, respectively. This band also experienced bathochromic shift on coordination to the metal between $1556-1507$ and $1542-1507 \mathrm{~cm}^{-1}$ for the $\mathrm{Co}(\mathrm{II})$ and $\mathrm{Cu}$ (II) complexes studied, respectively ${ }^{23-26}$. The calculated 'amide II' for both the $\mathrm{Co}(\mathrm{II})$ and $\mathrm{Cu}(\mathrm{II})$ complexes were at $1608-1598 \mathrm{~cm}^{-1}$ for PM3 and $1535-1525 \mathrm{~cm}^{-1}$ for DFT, respectively.

This $v(\mathrm{~N}-\mathrm{H})$ stretching frequency of the amino observed at $3539 \mathrm{~cm}^{-1}$ on coordination was lowered to between 3345 $3199 \mathrm{~cm}^{-1}$ for the $\mathrm{Co}$ (II) complexes while for the $\mathrm{Cu}$ (II) complexes the bands were observed between $3357-3278 \mathrm{~cm}^{-1}$. The observed values are consistent with previous studies ${ }^{23-26}$. The calculated values of $v(\mathrm{~N}-\mathrm{H})$ for the $\mathrm{Co}(\mathrm{II})$ and $\mathrm{Cu}(\mathrm{II})$ co mplexes appear at 3383-3196 and 3427-3264 $\mathrm{cm}^{-1}$ for PM3 and $3456-3257$ and $3498-3321 \mathrm{~cm}^{-1}$ for DFT, respectively. Although the vibrational frequencies calculated at DFT are closer to the experimentally determined values especially for amide I and amide II, the PM3 calculated IR followed quantitatively the same trend as the experimentally observed ones (Table-2). In addition, only the IR data calculated for $\mathrm{Cu}$ (II) and $\mathrm{Co}(\mathrm{II})$ complex ions involving the $\mathrm{O} 2$ and $\mathrm{N} 2$ atoms of 


\begin{tabular}{|c|c|c|c|c|c|c|c|c|}
\hline \multicolumn{9}{|c|}{$\begin{array}{l}\text { TABLE-1 } \\
\text { ANALYTICAL DATA OF LIGAND AND Co(II) AND Cu(II) COMPLEXES }\end{array}$} \\
\hline \multirow{2}{*}{ Compound } & \multirow{2}{*}{ Colour } & \multirow{2}{*}{$\begin{array}{l}\text { Yield } \\
(\%)\end{array}$} & \multirow{2}{*}{$\mu_{\text {eff }}(\mathrm{BM})$} & \multirow{2}{*}{ m.p. $\left({ }^{\circ} \mathrm{C}\right)$} & \multicolumn{4}{|c|}{ Metal observed (calcd.) (\%) } \\
\hline & & & & & M & $\mathrm{C}$ & $\mathrm{H}$ & $\mathrm{N}$ \\
\hline AAAH & White & 63 & - & $217-219$ & - & $41.22(41.37)$ & $6.86(6.94)$ & $23.68(24.13)$ \\
\hline $\mathrm{Co}[\mathrm{AAAH}]_{3}(\mathrm{OAc})_{2}$ & Purple & 61 & 5.24 & 194 & $11.07(11.22)$ & $36.42(36.58)$ & $5.68(5.76)$ & $16.22(16.00)$ \\
\hline $\mathrm{Co}[\mathrm{AAAH}]_{3} \mathrm{Cl}_{2}$ & Purple & 76 & 5.23 & 162 & $12.39(12.32)$ & $30.62(30.13)$ & $4.89(5.06)$ & $17.55(17.57)$ \\
\hline $\mathrm{Co}[\mathrm{AAAH}]_{3} \mathrm{SO}_{4}$ & Purple & 60 & 5.17 & 192 & $11.37(11.71)$ & $28.88(28.63)$ & $4.80(4.81)$ & $16.50(16.70)$ \\
\hline $\mathrm{Co}[\mathrm{AAAH}]_{3}\left(\mathrm{NO}_{3}\right)_{2}$ & Purple & 60 & 5.54 & 210 & 11.05 (11.09) & $27.33(27.13)$ & $4.55(4.55)$ & $21.00(21.09)$ \\
\hline $\mathrm{Cu}[\mathrm{AAAH}]_{2}(\mathrm{OAc})_{2}$ & Dirty-green & 55 & 1.54 & 146 & $15.00(15.35)$ & $34.62(34.83)$ & $4.57(5.36)$ & $13.65(13.54)$ \\
\hline $\mathrm{Cu}[\mathrm{AAAH}]_{2} \mathrm{Cl}_{2}$ & Dirty-green & 75 & 1.76 & 154 & $17.61(17.32)$ & $26.49(26.20)$ & $4.69(4.40)$ & $15.41(15.28)$ \\
\hline $\mathrm{Cu}[\mathrm{AAAH}]_{2} \mathrm{SO}_{4}$ & Dirty-green & 68 & 1.79 & 142 & $15.93(16.22)$ & $24.23(24.53)$ & $4.28(4.12)$ & $13.95(14.30)$ \\
\hline $\mathrm{Cu}[\mathrm{AAAH}]_{2}\left(\mathrm{NO}_{3}\right)_{2}$ & Dirty-green & 53 & 1.77 & 178 & $15.33(15.14)$ & $22.69(22.89)$ & $3.74(3.84)$ & $20.00(20.02)$ \\
\hline
\end{tabular}

TABLE-2

RELEVANT EXPERIMENTAL AND CALCULATED INFRARED SPECTRAL BANDS $\left(\mathrm{cm}^{-1}\right)$ OF LIGAND AND Co(II) AND Cu(II) COMPLEXES $\left(\mathrm{cm}^{-1}\right)$

\begin{tabular}{|c|c|c|c|c|c|c|}
\hline \multicolumn{2}{|c|}{ Compound } & Amide I & Amide II & $v(\mathrm{~N}-\mathrm{H})$ & $v(\mathrm{C}=\mathrm{O})$ & $v(\mathrm{C}-\mathrm{H})$ \\
\hline \multicolumn{2}{|c|}{ AAAH } & $1612(\mathrm{~m})$ & $1544(w)$ & $3539(w)$ & $1782(\mathrm{~m})$ & $2939(w)$ \\
\hline \multicolumn{2}{|c|}{$\mathrm{Co}(\mathrm{AAAH})_{3} \mathrm{Cl}_{2}$} & $1570(\mathrm{~s})$ & $1514(w)$ & 3333(w) & $1724(s)$ & 2913(w) \\
\hline \multicolumn{2}{|c|}{$\mathrm{Co}(\mathrm{AAAH})_{3}(\mathrm{OAc})_{2}$} & $1570(\mathrm{~s})$ & $1514(w)$ & $3290(w)$ & $1708(\mathrm{~m})$ & $2919(w)$ \\
\hline \multicolumn{2}{|c|}{$\mathrm{Co}(\mathrm{AAAH})_{3} \mathrm{SO}_{4}$} & $1570(\mathrm{~s})$ & $1556(w)$ & $3199(w)$ & $1712(s)$ & 2925(w) \\
\hline \multicolumn{2}{|c|}{$\mathrm{Co}(\mathrm{AAAH})_{3}\left(\mathrm{NO}_{3}\right)_{2}$} & $1566(\mathrm{~m})$ & $1507(w)$ & $3345(w)$ & $1700(s)$ & $2900(w)$ \\
\hline \multicolumn{2}{|c|}{$\mathrm{Cu}(\mathrm{AAAH})_{2} \mathrm{Cl}_{2}$} & $1563(\mathrm{~m})$ & $1542(s)$ & $3247(\mathrm{~m})$ & $1697(\mathrm{~m})$ & 2913(w) \\
\hline \multicolumn{2}{|c|}{$\mathrm{Cu}(\mathrm{AAAH})_{2}(\mathrm{OAc})_{2}$} & $1563(\mathrm{~m})$ & $1542(w)$ & $3357(w)$ & $1731(\mathrm{~m})$ & 2913(w) \\
\hline \multicolumn{2}{|c|}{$\mathrm{Cu}(\mathrm{AAAH})_{2} \mathrm{SO}_{4}$} & $1563(\mathrm{~m})$ & - & $3278(w)$ & $1703(\mathrm{~m})$ & $2960(w)$ \\
\hline \multicolumn{2}{|c|}{$\mathrm{Cu}(\mathrm{AAAH})_{2}\left(\mathrm{NO}_{3}\right)_{2}$} & $1566(\mathrm{~m})$ & $1507(\mathrm{~m})$ & $3345(w)$ & $1700(w)$ & - \\
\hline \multirow{2}{*}{ AAAH } & PM3 & 1704 & 1620 & $3385,3350,3350$ & 1964 & $3089,3080,2944$ \\
\hline & DFT & 1614 & 1540 & $3467,3365,3235$ & 1778 & $3256,3167,3051$ \\
\hline \multirow[t]{2}{*}{$\mathrm{Co}(\mathrm{AAAH})_{3}{ }^{2+}$} & PM3 & $1672,1610,1600$ & $1608,1601,1598$ & $\begin{array}{c}3383,3377,3326,3312 \\
3196\end{array}$ & $1960,1939,1931$ & $\begin{array}{c}3063,3013,3008,2933, \\
2931\end{array}$ \\
\hline & DFT & $1598,1557,1552$ & $1535,1532,1525$ & $3456,3426,3367,3257$ & $1742,1740,1732$ & $3256,3241,3172,2998$ \\
\hline \multirow[t]{2}{*}{$\mathrm{Cu}(\mathrm{AAAH})_{2}{ }^{2+}$} & PM3 & 1642,1645 & 1586,1508 & $3427,3422,3264$ & 1959,1932 & $\begin{array}{c}3070,3069,3065,2913, \\
2964,2913\end{array}$ \\
\hline & DFT & 1584,1560 & 1532,1523 & $3498,3364,3321$ & 1739,1736 & $3257,3232,2968,2962$ \\
\hline
\end{tabular}

the ligand formed coordinate bonds with the metal ions (i.e., complex A and complex D) which, are also in agreement with the experimental observations.

Structural features: The formation of both $\mathrm{Cu}(\mathrm{II})$ and $\mathrm{Co}(\mathrm{II})$ complex ions involving the $\mathrm{O} 2$ and $\mathrm{N} 2$ atoms of the ligand are thermodynamically and energetically favoured in forming coordinate bonds with the metal ions (i.e., complexes $\mathrm{A}$ and D) over those involving $\mathrm{O} 1$ and $\mathrm{N} 2$ atoms of the ligand (i.e., complexes B, C and E) as shown in Table-3. This is also in agreement with the experimentally predicted structures from spectroscopic data. Therefore, the selected geometric parameters of the most thermodynamically stable $\mathrm{Cu}$ (II) and $\mathrm{Co}$ (II) complex ions calculated at both semi-empirical (PM3) and DFT levels are displayed in Table-4.
The structural parameters calculated at semi-empirical (PM3) were quite different from those obtained at DFT. For instance, $\mathrm{Cu}-\mathrm{O} 1(\mathrm{Cu}-\mathrm{N} 1)$ bond lengths are $1.830 \AA$ (1.847 $\mathrm{\AA})$ and $1.842 \AA$ (1.845 $\AA$ ) for PM3 and DFT, respectively. The Co-O1 (Co-N1) bond lengths are $1.915 \AA$ (1.926 $\AA$ ) and 1.860 $\AA$ (1.857 $\AA$ ) for PM3 and DFT, respectively. Also, the bond angles calculated at PM3 are slightly different from those calculated at DFT level (Table-4). Generally, both PM3 and DFT methods showed that M-O and M-N calculated for $\mathrm{Cu}$ (II) complex ion are shorter than that of $\mathrm{Co}$ (II) complex ion. However, based on the infrared data that showed close correlation between experimentally observed values and DFT calculations, the structural data calculated at DFT are expected to be closer to the experimental values than that of PM3.

TABLE-3

CALCULATED RELATIVE ENERGIES (REL. E), HOMO, LUMO AND DIPOLE MOMENT AT SEMI-EMPIRICAL (PM3) AND B3LYP/6-31G* LEVELS

\begin{tabular}{|c|c|c|c|c|c|}
\hline & \multicolumn{3}{|c|}{$\mathrm{Cu}$ (II) complex ions } & \multicolumn{2}{|c|}{$\mathrm{Co}$ (II) complex ions } \\
\hline & Sq-planar & Trans & Cis & Nor. Octah. & Bend Octah. \\
\hline Rel. E & $0.00(0.00)^{*}$ & $122.06(165.54)$ & $87.34(114.20)$ & $0.00(0.00)$ & $179.02(270.77)$ \\
\hline $\mathrm{H}(\mathrm{eV})$ & $-12.80(-16.06)$ & $-12.82(-16.10)$ & $-12.31(-16.82)$ & $-12.46(-15.98)$ & $-12.53(-15.06)$ \\
\hline $\mathrm{L}(\mathrm{eV})$ & $-7.57(-9.13)$ & $-7.68(-9.53)$ & $-7.09(-8.83)$ & $-7.44(-9.58)$ & $-7.56(-9.76)$ \\
\hline$\Delta(\mathrm{H}-\mathrm{L}) \mathrm{eV}$ & $5.23(6.93)$ & $5.14(6.57)$ & $5.22(7.99)$ & $5.02(6.40)$ & $4.97(5.30)$ \\
\hline D.M (debye) & $3.54(4.98)$ & $6.67(9.24)$ & $3.21(3.65)$ & $3.55(4.97)$ & $7.32(10.19)$ \\
\hline
\end{tabular}

*PM3 values in bracket. Relative energies (Rel. E), HOMO (H), LUMO (L) and dipole moment (DM). 


\begin{tabular}{|c|c|c|c|c|c|}
\hline \multicolumn{6}{|c|}{$\begin{array}{c}\text { TABLE-4 } \\
\text { SELECTED GEOMETRICAL PARAMETERS OF MOST STABLE Cu(II) } \\
\text { AND Co(II) COMPLEX IONS CALCULATED AT PM3 AND B3LYP/6-31G* LEVELS }\end{array}$} \\
\hline \multicolumn{3}{|c|}{$\mathrm{Cu}(\mathrm{II})$ complex ion } & \multicolumn{3}{|c|}{ Co(II) complex ion } \\
\hline Bond length $(\AA)$ & PM3 & DFT & Bond length $(\AA)$ & PM3 & DFT \\
\hline $\mathrm{Cu}-\mathrm{O} 1$ & 1.830 & 1.842 & $\mathrm{Co}-\mathrm{O} 1$ & 1.915 & 1.926 \\
\hline $\mathrm{Cu}-\mathrm{O} 2$ & 1.851 & 1.855 & $\mathrm{Co}-\mathrm{O} 2$ & 1.922 & 1.967 \\
\hline $\mathrm{Cu}-\mathrm{N} 1$ & 1.847 & 1.845 & $\mathrm{Co}-\mathrm{O} 3$ & 1.917 & 1.922 \\
\hline $\mathrm{Cu}-\mathrm{N} 2$ & 1.840 & 1.843 & Co-N1 & 1.860 & 1.857 \\
\hline \multicolumn{3}{|c|}{ Bond angle $(\AA)$} & Co-N2 & 1.852 & 1.865 \\
\hline $\mathrm{O} 1-\mathrm{Cu}-\mathrm{O} 2$ & 175.75 & 176.80 & $\mathrm{Co}-\mathrm{N} 3$ & 1.820 & 1.821 \\
\hline $\mathrm{O} 1-\mathrm{Cu}-\mathrm{N} 1$ & 89.84 & 86.07 & \multicolumn{3}{|c|}{ Bond angle $(\AA)$} \\
\hline $\mathrm{O} 1-\mathrm{Cu}-\mathrm{N} 2$ & 90.88 & 92.34 & O1-Co-O2 & 88.09 & 89.98 \\
\hline $\mathrm{O} 2-\mathrm{Cu}-\mathrm{N} 1$ & 91.22 & 90.89 & $\mathrm{O} 1-\mathrm{Co}-\mathrm{O} 3$ & 179.66 & 177.35 \\
\hline $\mathrm{O} 2-\mathrm{Cu}-\mathrm{N} 2$ & 88.50 & 89.65 & O1-Co-N1 & 86.97 & 87.05 \\
\hline $\mathrm{N} 1-\mathrm{Cu}-\mathrm{N} 2$ & 173.91 & 172.87 & O1-Co-N2 & 88.08 & 89.22 \\
\hline- & - & - & O1-Co-N3 & 93.27 & 92.95 \\
\hline- & - & - & O2-Co-N1 & 83.78 & 86.11 \\
\hline- & - & - & $\mathrm{O} 2-\mathrm{Co}-\mathrm{N} 2$ & 83.56 & 82.90 \\
\hline- & - & - & $\mathrm{O} 2-\mathrm{Co}-\mathrm{N} 3$ & 178.47 & 177.66 \\
\hline- & - & - & O3-Co-N1 & 93.14 & 91.26 \\
\hline- & - & - & $\mathrm{O} 3-\mathrm{Co}-\mathrm{N} 2$ & 91.74 & 90.65 \\
\hline- & - & - & O3-Co-N3 & 87.04 & 89.03 \\
\hline- & - & - & N1-Co-N2 & 166.55 & 170.42 \\
\hline- & - & - & N1-Co-N3 & 95.59 & 92.09 \\
\hline- & - & - & $\mathrm{N} 2-\mathrm{Co}-\mathrm{N} 3$ & 97.70 & 100.22 \\
\hline
\end{tabular}

The Frontier molecular orbitals for the complex (A) and (D) computed at the DFT level are shown in Fig. 2. The HOMO and the $\mathrm{LUMO}$ of $\mathrm{Cu}(\mathrm{AAAH})_{2}{ }^{2+}$ ion are mainly localized on carbonyl and amide II regions of the ligand, respectively, while both the HOMO and LUMO of the $\mathrm{Co}(\mathrm{AAAH})_{3}{ }^{2+}$ ion localized around the central metal ions (Fig. 2). The Mulliken atomic charges for copper, cobalt, oxygen and nitrogen atoms are displayed in Table-5. The Mulliken charges of copper and cobalt atoms are -0.429 and -0.226 , respectively. In both $\mathrm{Cu}(\mathrm{AAAH})_{2}{ }^{2+}$ and $\mathrm{Co}(\mathrm{AAAH})_{3}{ }^{2+}$ ions, lower values of Mulliken charges on nitrogen and oxygen atoms that are directly bonded to the central metal ion was observed. This was an evident that charges are transferred from ligand to the central metal ion during complex formation.

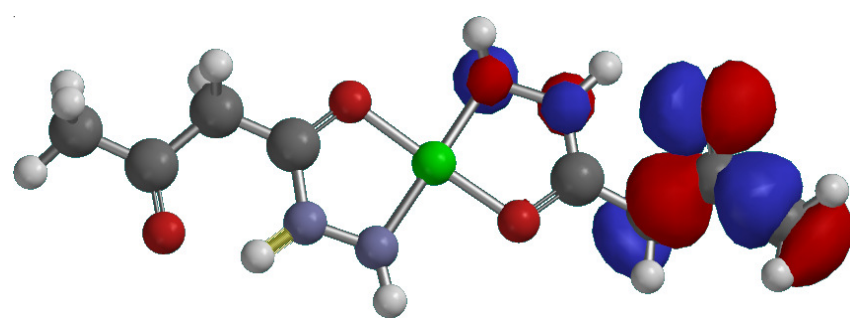

HOMO

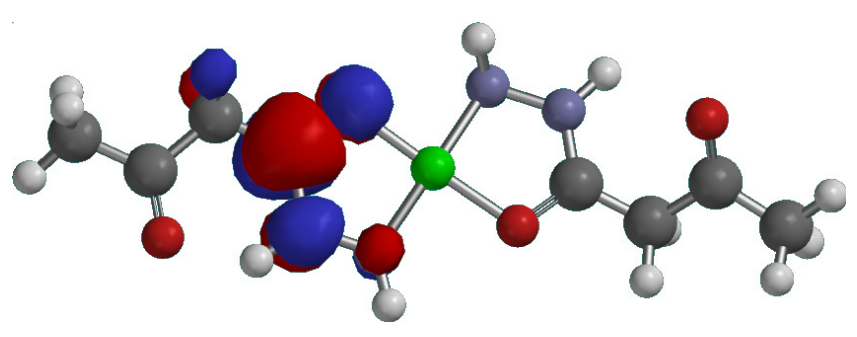

LUMO

(A)

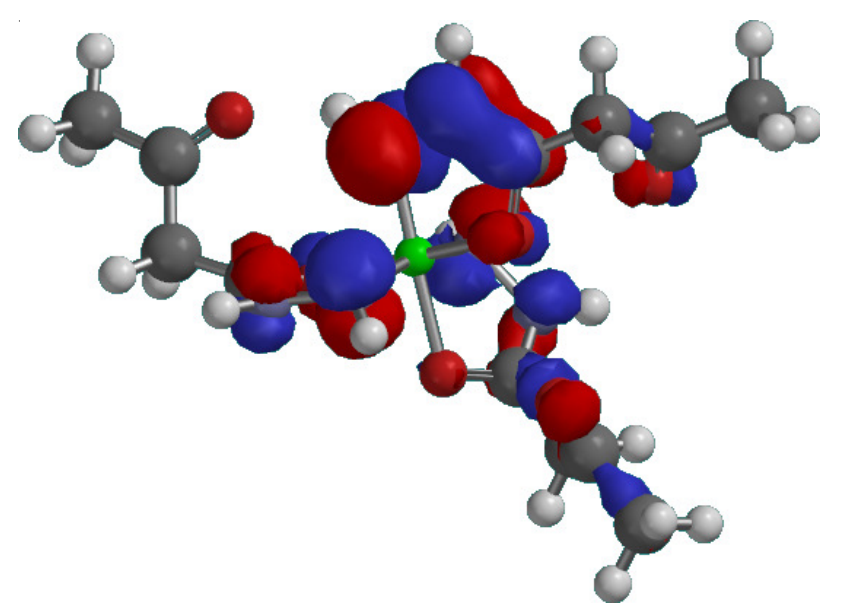

HOMO

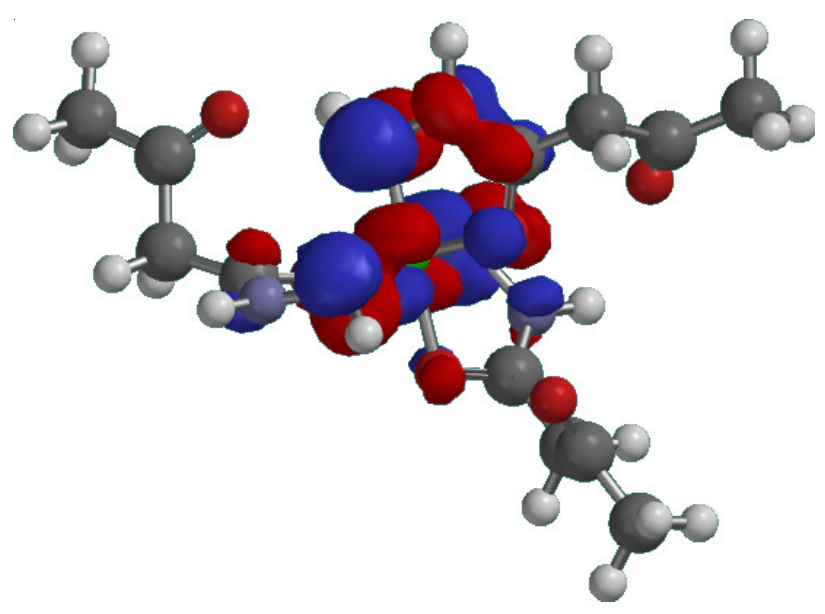

LUMO

(D)

Fig. 2. Frontier molecular orbital: $\mathrm{HOMO}$ and $\mathrm{LUMO}$ of the $\mathrm{Cu}(\mathrm{AAAH})_{2}{ }^{2+}$ (A) and $\mathrm{Co}(\mathrm{AAAH})_{3}{ }^{2+}(\mathrm{D})$ ions 
TABLE-5

MULLIKEN CHARGES OF THE COMPLEX A AND D IONS

\begin{tabular}{ccc}
\hline Atom & Complex A & Complex D \\
\hline $\mathrm{N} 1$ & 0.246 & 0.024 \\
$* \mathrm{~N} 2$ & 0.029 & 0.156 \\
$\mathrm{~N} 3$ & 0240 & 0.146 \\
$* \mathrm{~N} 4$ & 0.150 & 0.042 \\
$\mathrm{~N} 5$ & - & 0.171 \\
*N6 & - & 0.131 \\
*O1 & -0.004 & -0.235 \\
*O2 & -0.069 & -0.257 \\
*O3 & - & -0.139 \\
${ }^{\mathrm{a}} \mathrm{O} 4$ & -0.348 & -0.385 \\
${ }^{\mathrm{a}} \mathrm{O} 5$ & -0.371 & -0.310 \\
${ }^{\mathrm{a}} \mathrm{O} 6$ & - & -0.345 \\
$\mathrm{M}$ & -0.429 & -0.226 \\
\hline
\end{tabular}

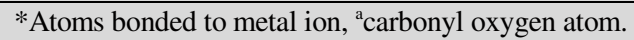

Electronic spectra: The electronic reflectance spectra of the ligand and complexes are presented in Table-6. In the ultraviolet spectra of the acetoacetic acid hydrazide, the $n \rightarrow \pi^{*}$ transition observed at $51,282 \mathrm{~cm}^{-1}$ attributed to the excitation of a nitrogen lone pair of electron to the antibonding $\sigma^{*}$ orbital of the amino group was shifted to $48,077-51,020 \mathrm{~cm}^{-1}$ in the spectra of the complexes. The $\pi \rightarrow \pi^{*}$ transition in the carbonyl group observed at $37,175 \mathrm{~cm}^{-1}$ in the ligand also experienced bathochromic shifts to $c a .36,496 \mathrm{~cm}^{-1}$ upon complexation in all the compounds. An additional band observed in the ultraviolet spectra of the complexes between 31,646$33,223 \mathrm{~cm}^{-1}$ was attributed to $\pi \rightarrow \pi *$ transition. The charge transfer transitions were observed at $23,256-29,497 \mathrm{~cm}^{-1}$ in the complexes ${ }^{12,13,23-26}$.

In the visible spectra of octahedral cobalt(II) complexes, three electronic transitions; ${ }^{4} \mathrm{~T}_{1 \mathrm{~g}} \rightarrow{ }^{4} \mathrm{~T}_{2 \mathrm{~g}},{ }^{4} \mathrm{~T}_{1 \mathrm{~g}} \rightarrow{ }^{4} \mathrm{~A}_{2 \mathrm{~g}}$ and ${ }^{4} \mathrm{~T}_{1 \mathrm{~g}}$ $\rightarrow{ }^{4} \mathrm{~T}_{1 \mathrm{~g}}(\mathrm{P})$ which is represented by $v_{1}, v_{2}$ and $v_{3}$, respectively ${ }^{27}$. The experimentally observed transitions are $\mathrm{Co}[\mathrm{AAAH}]_{3}(\mathrm{OAc})_{2}$ with transitions at 9,434 and $20,284 \mathrm{~cm}^{-1}$ was assigned to ${ }^{4} \mathrm{~T}_{\mathrm{lg}}$ $\rightarrow{ }^{4} \mathrm{~T}_{2 \mathrm{~g}}$ and ${ }^{4} \mathrm{~T}_{1 \mathrm{~g}} \rightarrow{ }^{4} \mathrm{~T}_{1 \mathrm{~g}}(\mathrm{P})$, respectively. The Co[AAAH $]_{3} \mathrm{Cl}_{2}$, $\mathrm{Co}[\mathrm{AAAH}]_{3}\left(\mathrm{NO}_{3}\right)_{2}$ and $\mathrm{Co}[\mathrm{AAAH}]_{3} \mathrm{SO}_{4}$ complexes had only one observable ${ }^{4} \mathrm{~T}_{\mathrm{lg}} \rightarrow{ }^{4} \mathrm{~T}_{\mathrm{lg}}(\mathrm{P})$ transitions at the absorption peaks $17,241,18,767$ and $20,408 \mathrm{~cm}^{-1}$, respectively.

The electronic reflectance spectra of the copper(II) complexes displays broad bands at $13,699-16,155 \mathrm{~cm}^{-1}$. These bands observed in the spectra of the $\mathrm{Cu}$ (II) complexes are assignable to ${ }^{2} \mathrm{~T}_{2} \rightarrow{ }^{2} \mathrm{E}$ transitions which is consistent with a square planar geometry ${ }^{28}$.

Magnetic moment: The Co(II) complexes studied display effective magnetic moments $\left(\mu_{\text {eff }}\right)$ between 5.17-5.54 BM. Cobalt(II) complexes in octahedral environments have observed magnetic moments around 4.8-5.2 BM at room temperature ${ }^{29}$, which favourably compare with those of the acetoacetate complexes studied. The copper(II) complexes display the effective magnetic moments $\left(\mu_{\text {eff }}\right)$ in the range 1.76$1.79 \mathrm{BM}$ except $\mathrm{Cu}[\mathrm{AAAH}]_{2}(\mathrm{OAc})_{2}$ with $1.54 \mathrm{BM}$. Most of the copper(II) complexes agrees with the spin-only value $\left(\mu_{\mathrm{s.o}}\right)$ of $1.73 \mathrm{BM}$. In the $\mathrm{Cu}[\mathrm{AAAH}]_{2}(\mathrm{OAc})_{2}$ complex, a reduction in the $\left(\mu_{\text {eff }}\right)$ to $1.54 \mathrm{BM}$ from the spin-only value of $1.73 \mathrm{BM}$ observed can be attributed to strong $\mathrm{Cu}-\mathrm{Cu}$ interactions in the crystal lattice of the compound ${ }^{29}$.

The experimental data thus obtained are consistent with the following structures of the complexes (Fig. 3).
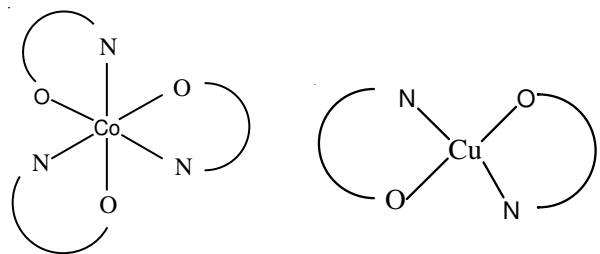

$\mathrm{C}=\mathrm{CH}_{3} \mathrm{COCH}_{2} \mathrm{CONHNH}_{2} ; \mathrm{X}=\mathrm{CH}_{3} \mathrm{COO}, \mathrm{Cl}_{2}, \mathrm{NO}_{3}$ or $0.5 \mathrm{SO}_{4}$ Fig. 3. Suggested structures for the complexes

\section{Conclusion}

The elemental and spectroscopic studies revealed that the cobalt(II) ions are in an octahedral environment while the copper(II) metal complexes adopt a square planar geometry. This is further supported by the room temperature magnetic susceptibility measurements and the quantum chemical studies employed using semi-empirical PM3 and density functional theory (DFT) methods. The DFT method appears to compare favourably well with spectra interpretations obtained from the experimental work while the PM3 though slightly different also point to the same trend observed with DFT in both the spectral and structural features obtained.

\section{REFERENCES}

1. N. Galic, B. Peric, B. Kojic-Prodic and Z. Cimerman, J. Mol. Struct., 559, 187 (2001).

2. J. Singh and P. Singh, Bioinorg. Chem. Appl., Article ID 104549 (2012).

3. W. Plass, A. Pohlmann and Y. Hakan-Peter, J. Inorg. Biochnol., 80, 181 (2000).

4. Vivekanand and N.S. Bhandari, Asian J. Chem., 19, 4225 (2007).

5. L. David, M. Rusu, O. Cozar, D. Rusu, M. Todica and C. Balam, J. Mol. Struct., 482-483, 149 (1999).

6. G.I. Zubareva, S.U. Adeev, A.V. Radushev, A.I. Gomzikov and M.P. Zubarev, Russ. J. Appl. Chem., 71, 283 (1998).

7. M.A. Mohammed, Polym. Degrad. Stab., 56, 317 (1997).

8. A.V. Radushev, M.M. Malyshara, O. V. Deryabina, T.G. Ramodina, A.M. Lopanev and G.K. Kulmukhamedov, Patent Izobreteniya, 22, 253 (1992).

\begin{tabular}{lcccc} 
& \multicolumn{3}{c}{ TABLE-6 } \\
& \multicolumn{1}{c}{ ELECTRONIC SPECTRAL TRANSITIONS FOR THE LIGAND AND COMPLEXES $\left(\mathrm{cm}^{-1}\right)$} \\
\hline \multicolumn{1}{c}{ Compound } & $d-d$ & $\mathrm{CT}$ & Intra ligand transitions \\
\hline AAAH & - & - & 51,$282 ; 37,175$ \\
$\mathrm{Co}(\mathrm{AAAH})_{3}(\mathrm{OAc})_{2}$ & 20,$284 ; 9,434$ & 29,$497 ; 27,855$ & 50,$251 ; 47,393 ; 36,496 ; 31,646$ \\
$\mathrm{Co}(\mathrm{AAAH})_{3} \mathrm{Cl}_{2}$ & 17,241 & - & - \\
$\mathrm{Co}(\mathrm{AAAH})_{3} \mathrm{SO}_{4}$ & 20,408 & - & 51,$020 ; 47,393 ; 31,646$ \\
$\mathrm{Co}(\mathrm{AAAH})_{3}\left(\mathrm{NO}_{3}\right)_{2}$ & 18,767 & 28,653 & 48,$077 ; 45,455 ; 31,646$ \\
$\mathrm{Cu}(\mathrm{AAAH})_{2}\left(\mathrm{OAc}_{2}\right.$ & 15,060 & - & 48,$077 ; 38,168 ; 36,496$ \\
$\mathrm{Cu}(\mathrm{AAAH})_{2} \mathrm{Cl}_{2}$ & 13,699 & - & - \\
$\mathrm{Cu}(\mathrm{AAAH})_{2} \mathrm{SO}_{4}$ & 14,286 & - & - \\
$\mathrm{Cu}(\mathrm{AAAH})_{2}\left(\mathrm{NO}_{3}\right)_{2}$ & 16,155 & 23,256 & 50,$251 ; 36,496 ; 33,223$ \\
\hline
\end{tabular}


9. A.V. Radushev, N.F. Petina, G.J. Popov and N.B. Tavasova, Zaschch Met., 28, 845 (1992).

10. A.V. Radushev, V.Y. Gusher and G.S. Bogomazova, Zh. Neorg. Khim, 37, 2292 (1992).

11. A.M. Gad, A. El-Dissouky, E.M. Mansour and A. El-Maghraby, Polym. Degrad. Stab., 68, 153 (2001).

12. F.A. Adekunle, J.A.O. Woods, I.O. Adeoye, O.O.E. Onawumi and O.A. Odunola, Res. J. Pharm. Biol. Chem. Sci., 1, 425 (2010).

13. F.A. Adekunle, J.A.O. Woods, O.O.E. Onawumi and O.A. Odunola, Synth. React. Inorg. Met.-Org. Nano-Met. Chem., 40, 430 (2010).

14. J. Basset, R.C. Denney, G.H. Jeffery and J. Mendham, Vogel's Textbook of Quantitative Inorganic Analysis, Longman Scientific and Technical, London, 316-322 (1986).

15. J.S. Johnson and D.A. Evans, Acc. Chem. Res., 33, 325 (2000).

16. L. Bernabé, B.L. Rivas, V. Gloria, G.V. Seguel, E. Kurt and K.E. Geckeler, J. Appl. Polym. Sci., 86, 1015 (2001)

17. G.V. Seguel, B.I. Rivas and C. Novas, J. Chil. Chem. Soc., 50, 401 (2005).

18. I.O. Adeoye, O.A. Odunola, M.A. Oladipo and B. Semire, E-J. Chem., 7, 517 (2010).

19. G.V. Seguel, B.I. Rivas and C. Paredes, J. Chil. Chem. Soc., 55, 355 (2010).
20. F.A. Adekunle, O.A. Odunola, M.A. Oladipo and B. Semire, E-J. Chem., 7, 517 (2010)

21. P.J. Stephens, F.J. Devlin, C.F. Chabalowski and M.J. Frisch, J. Phys. Chem., 98, 11623 (1994).

22. A.D. Becke, J. Chem. Phys., 98, 5648 (1993).

23. D.N. Kushev, N.C. Spassovska, S.I. Taxirov and K.C. Grancharov, Z. Naturforsch., 52c, 49 (1997).

24. P.R. Bonchev, M. Boneva and M. Mitera, Inorg. Nucl. Chem. (Dublin), 43, 3163 (1981).

25. O.A. Odunola, I.O. Adeoye and J.A.O. Woods, Synth. React. Inorg. Met.Org. Chem., 32, 801 (2002).

26. O.A. Odunola, I.O. Adeoye, J.A.O. Woods and A.C. Gelebe, Synth. React. Inorg. Met.-Org. Chem., 33, 205 (2003).

27. Y.Y. Kharitonov, T.V. Shalamberidze, R.I. Machkhoshivili, E.K. Shestakova and D.N. Bugianishivili, Russ. J. Inorg. Chem., 24, 1104 (1979).

28. M.M. Kamal, Z.A. Ahmed and A.A.M. Aly, Synth. React. Inorg. Met.Org. Chem., 21, 99 (1991).

29. N.N. Greenwood and A. Earnshaw, Chemistry of the Elements Elsevier Oxford, pp. 129-1132 (1997). 